\title{
NOTAS E DESCRIÇÕES EM DESMIPHORINI (COLEOPTERA, CERAMBYCIDAE, LAMIINAE), COM UMA REVISÃO DO GÊNERO MIMASYNGENES BREUNING
}

\author{
Maria Helena M. Galileo ${ }^{1}$ \\ Ubirajara R. Martins ${ }^{2}$
}

\begin{abstract}
Notes AND DESCRIPTIONS ON DESMipHorini (COleoptera, CERAMBYClDaE, Laminae) WITH a Revision of THE genUs Mimasyngenes Breuning. Notes and keys to the species of Ischnoleomimus Breuning 1940; Malthonea Thomson, 1864 and Mimasyngenes Breuning, 1950 are given. Parablabia Breuning, 1959 is considered a synonym of Malthonea Thomson, 1864, and the following new combinations are made: M. guttata (Kirsch, 1889), comb n. and M. ruficornis Belon, 1903, both transferred from Parablabia. New taxa described: Ischnolea piim sp.n. (Bolívia); Ischnoleomimus foveatus sp.n. (Bolívia); Malthonea cumbica sp.n. (Venezuela); Cicuiara gen.n., type species Exocentrus striatus Bates, 1866; E. nitidulus Bates, 1866 is transferred to Cicuiara; Mimasyngenes quiuira sp.n. (Brazil, São Paulo); M. icuapara sp.n. (Brasil, São Paulo; Argentina, Misiones); M. ytu sp.n. (Brazil, Minas Gerais and São Paulo). Additional records are provided for; Ischnoleomimus excavatus Breuning, 1940; Malthonea guttata (Kirsch, 1889): M. ruficornis Belon, 1903; Cicuiara striata (Bates, 1866); Mimasyngenes lineatipennis Breuning, 1950 and M. inlineatus Breuning, 1956.

KEY WORDS. Cerambycidae, Desmiphorini, Ischnoleomimus, Malthonea, Mimasyngenes
\end{abstract}

BREUNING (1974) apresentou uma revisão das espécies americanas da tribo Desmiphorini, que contém diversos erros e omissões que devem ser corrigidos. Suas chaves para identificação mencionam único caráter em cada dilema; freqüentemente esses caracteres são de difícil interpretação pela ambigüidade. Além disso, suas redescrições específicas são comparativas, os dados de procedência são habitualmente vagos e as ilustrações em pequeno número.

Uma revisão do trabalho de BREUNING (1974) faz-se necessária, mas como a tribo envolve considerável número de táxons, dezenas deles ainda inéditos, optou-se por rever separadamente gêneros ou grupos de gêneros. Algumas contribuições já foram publicadas: revisão dos gêneros -Ischnolea (GALILEO \& MARTINS 1993a); Panegyrtes (GALILEO \& MARTINS 1993b, no prelo); Stereomerus (MARTINS \& GALILEO 1994); Coeloprocta (MARTINS \& GAlileo 1995a); Parischnolea, Cicatrisestola e Cymatonycha (MARTIns \& GALILEO 1995b); Malthonea (MARTINS \& GAlileo 1995c); Blabia (MARTINS \& GALILEO 1995d).

1) Museu de Clências Naturais, Fundação Zoobotânica do Rio Grande do Sul. Caixa Postal 1188, 90001-970 Porto Alegre, Rio Grande do Sul, Brasil. Pesquisadora do CNPq.

2) Museu de Zoologia, Universidade de São Paulo. Caixa Postal 7172, 01064-970 São Paulo, São Paulo, Brasil. Pesquisador do CNPq. 
Neste trabalho apresenta-se a revisão do gênero Mimasyngenes, descreve-se novos táxons e sinonimiza-se Parablabia Breuning, 1959 com Malthonea Thomson, 1864; além disso, registra-se novas ocorrências para algumas espécies.

As referências sob cada táxon restringem-se à descrição original e a citação do catálogo de MONNÉ (1994) onde as citações bibliográficas estão completas.

Abreviaturas mencionadas no texto: (BMNH) The Natural History Museum, Londres; (CMNH) Carnegie Museum of Natural History, Pittsbourgh; (FAUV) Facultad de Agronomia, Universidad Central de Venezuela, Maracay; (MCNZ) Museu de Ciências Naturais, Fundação Zoobotânica do Rio Grande do Sul, Porto Alegre; (MNRJ) Museu Nacional, Universidade Federal do Rio de Janeiro, Rio de Janeiro; (MZSP) Museu de Zoologia, Universidade de São Paulo, São Paulo; (NRMS) Naturhistoriska Riksmuseet, Estocolmo.

Todas as dimensões são fornecidas em milímetros.

\section{Ischnolea piim sp.n.}

Fig. 1

Etimologia. Tupi piím = furado; alusivo à densa pontuação do mesosterno.

Fêmea. Tegumento castanho, mais avermelhado nos élitros. Pubescência corporal amarelada, mais compacta numa faixa longitudinal no dorso do pronoto. Élitros com pubescência branco-suja no terço basal, com faixa oblíqua, mais clara, pouco contrastante, do terço anterior à sutura, que atinge áreas do meio, segue pela linha sutural até o terço apical, onde se volta para a margem em ramo muito estreito e descontínuo; essa faixa envolve mancha acastanhada, pequena e oblíqua; região ante-apical com algumas máculas de pubescência esbranquiçada. Lobos oculares inferiores mais longos que as genas; lobos superiores com sete fileiras de omatídios, tão distantes entre si quanto o dobro da largura de um lobo. Antenas atingem a extremidade dos élitros na porta do antenômero VII. Gibosidades do pronoto quase inaparentes. Pontuação pronotal fina e densa. Espinho lateral do protórax evidente com ápice ligeiramente voltado para trás. Escutelo com pubescência amarelada. Pontos da base dos élitros não tuberculados; extremidades elitrais obliquamente truncadas, desarmadas. Meso- e metafềmures com pontos contrastantes. Prosterno, mesosterno, mesepisternos e lados do metasterno grosseira e densamente pontuados. Lados dos urosternitos esparsamente pontuados.

Dimensões. Comprimento total, 10,9; comprimento do protórax, 1,8; maior largura do protórax, 2,7; comprimento do élitro, 8,1; largura umeral, 3,6.

Material-tipo. Holótipo fêmea. BolíviA, Sur Yungas: Chulumani, I-1948, Bridarolli leg., Coleção J.M. Bosq (MNRJ).

Discussão. Pela ausência de faixa estreita de pubescência compacta, oblíqua na metade basal dos élitros e de pequenas manchas de pubescência espalhadas por toda superfície, pelas extremidades elitrais desarmadas, e pelas coxas e fêmures concolores, I. piim assemelha-se mais e I. oculata Galileo \& Martins, 1993 e I. indistincta Breuning, 1942. Separa-se imediatamente de ambas pelos lados do metasterno densamente pontuados; nessas duas espécies o metasterno é praticamente liso. 

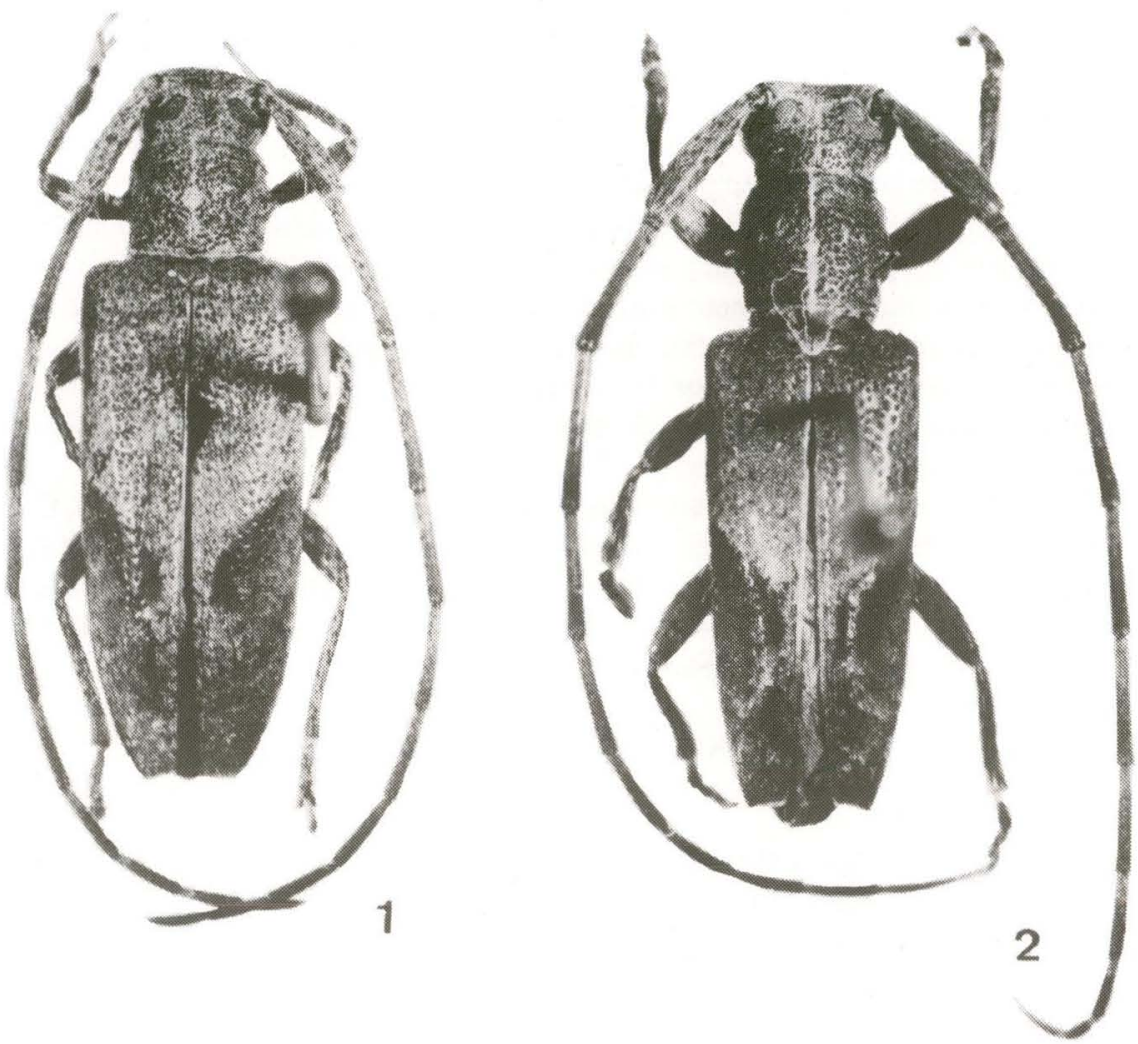

Figs 1-2. (1) Ischnolea piim sp.n., holótipo fêmea, comprimento, 10,9mm; (2) Ischnoleomimus excavatus Breuning, 1940, macho de Cacoal, Rondônia, comprimento, 9,5mm.

\section{Ischnoleomimus Breuning, 1940}

Ischnoleomimus Breuning, 1940: 168; Monné, 1994: 55 (cat.).

BREUNING (1974: 3), nos dilemas 40 e 41 de sua chave para os gêneros de Desmiphorini separa Ischnoleomimus de Ischnolea e de Estoloides pela fórmula antenal: antenômero III tão longo quanto o escapo para Ischnoleomimus e antenômero III mais longo do que o escapo para os outros dois.

Essa distinção parece pouco precisa. Uma característica mais palpável para distinguir Ischnoleomimus de Ischnolea e de Estoloides é a presença de tubérculo no processo mesosternal naquele gênero, enquanto que nestes o processo mesosternal é plano ou deprimido.

Como em algumas espécies de Ischnolea, os machos das espécies de Ischnoleomimus apresentam orifícios guarnecidos de pêlos claros e abundantes na face inferior dos metafêmures. 


\section{Ischnoleomimus excavatus Breuning, 1940}

Fig. 2

Ischnoleomimus excavatus Breuning, 1940: 168; Monné, 1994; 55 (cat.).

Originalmente descrita do Peru, Huallaga, Rio Mixiolo, examinou-se o diapositivo do holótipo fotografado por Moure no MNHN.

Tegumento castanho-escuro ou castanho-avermelhado escuro; espinho lateral do protórax pequeno, pouco saliente; faixa longitudinal de pubescência brancoamarelada do meio do pronoto estreita; escutelo com pubescência amarelada mais concentrada nas bordas; mancha lateral dos élitros de pubescência castanho-escura conspícua, com borda anterior nitidamente oblíqua em sentido descendente da margem para a sutura; tubérculo do processo mesosternal menos desenvolvido do que em I. foveatus sp.n.

Material examinado. PERU, Junin: Chanchamayo, fêmea, 22-XI-1949, Coll. H. Zellibor (MNRJ). Huanuco: Tingo Maria, macho, 16-XII-1946, Kuschel leg., ex-col. Bosq (MNRJ). BrasiL, Rondônia: Cacoal (Gleba 12, lote 6), macho, 15-IV-1980, Fernando C.Z. leg. (MZSP); Ouro Preto do Oeste, fêmea, XII-1963, B. Silva leg. (MZSP). Pará: Santarém, fêmea, Acc. 2966 (CMNH).

\section{Ischnoleomimus foveatus sp.n.}

Fig. 3

Macho. Tegumento avermelhado. Pubescência de maneira geral brancoavermelhada. Fronte densamente pontuada. Lobos oculares inferiores apenas mais longos que as genas; lobos oculares superiores com sete fileiras de omatídios, tão distantes entre si quanto o dobro da largura de um lobo. Vértice profundamente pontuado. Antenas atingem a extremidade dos élitros aproximadamente no ápice no antenômero VII. Escapo com pontos contrastantes. Base dos flagelômeros discretamente mais clara. Espinho lateral do protórax conspícuo. Pronoto densa e profundamente pontuado com faixa centro-longitudinal de pubescência amarelada. Escutelo recoberto por pubescência amarelada exceto estreita faixa central. Élitros com pubescência esparsa esbranquiçada na metade anterior; área centro-lateral dos élitros com revestimento mais esparso; terço apical com faixa estreita, oblíqua, de pubescência esbranquiçada, marmorada de castanho; sexto apical revestido com o mesmo tipo de pubescência. Ápices elitrais transversalmente truncados com espículo externo. Processo mesosternal com tubérculo protuberante. Meso- e metafêmures com pontos contrastantes. Face inferior dos metafêmures com orifício central, alongado, bordejado por pêlos densos, longos e amarelados.

Fêmea. Antenas atingem o ápice elitral na extremidade do antenômero VIII. Metafêmures esbeltos, sem depressão e pubescência diferenciada.

Dimensões, macho/fêmea. Comprimento total, 9,0-11,6/10,4-11,7; comprimento do protórax, 1,7-2,4/1,9-2,0; maior largura do protórax, 2,3-3,3/2,8-3,0; comprimento elitral, 6,3-8,1/7,4-8,5; largura umeral, 2,6-3,8/3,2-3,5.

Material-tipo. Holótipo macho. Bolívia, Prov. del Sara: Steinbach leg., Acc. 5043 (CMNH). Parátipos: 2 machos, mesmos dados do holótipo (MZSP); 
fêmea, mesmos dados do holótipo, XII-1912, (CMNH). Prov. Chapare, fêmea, 8-X-1945, H. Zellibor leg. (MNRJ).
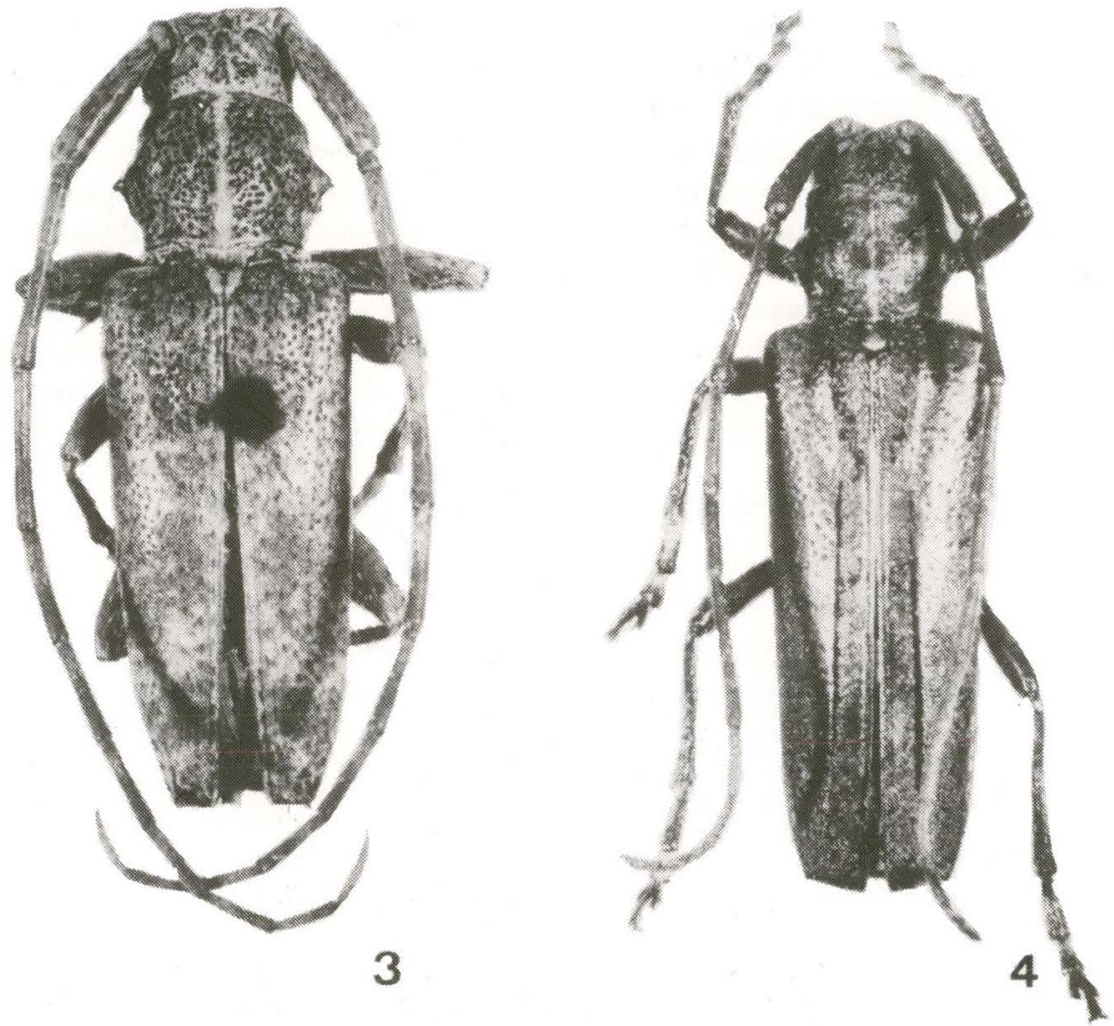

Figs 3-4. (3) Ischnoleomimus foveatus sp.n., holótipo macho, comprimento, 10,7mm; (4) Malthonea cumbica sp.n., holótipo macho, comprimento, 10,7mm.

\section{Chave para as espécies Ischnoleomimus}

1. Espinho lateral do protórax reduzido, mais curto que o pedicelo; mancha oblíqua de pubescência castanha centro-lateral dos élitros nitidamente demarcada; pubescência esbranquiçada do escutelo esparsa em toda a superfície e mais concentrada nas bordas (Fig. 2). Peru. Brasil (Rondônia, Pará) . . . . . . . . ................................ excavatus Breuning, 1940

- Espinho lateral do protórax projetado, tão longo quanto o pedicelo; sem mancha oblíqua de pubescência castanha no meio dos lados dos élitros; pubescência do escutelo não reveste faixa central longitudinal (Fig. 3). Bolívia ........ . foveatus sp.n. 


\section{Malthonea Thomson, 1864}

Malthonea Thomson, 1864: 329; Martins \& Galileo, 1995c: 611.

Blabia (Malthonea); Breuning, 1963: 514 (cat.); Monné, 1994: 66 (cat.)

Parablabia Breuning, 1959: 86; Monné, 1994: 66 (cat.). Syn.n.

Estabelecido por THOMSON (1864), Malthonea foi considerado subgênero de Blabia por BREUNING (1963). O status genérico foi restabelecido e o gênero foi revisto por MARTINS \& GALILEO (1995c).

Parablabia foi criado por BREUNING (1959) para Ptericoptus guttatus Kirsch, 1889; em 1963 o mesmo autor incluiu no gênero Malthonea ruficornis Belon, 1903. O caráter adotado por BREUNING (1974) para separar Parablabia de Malthonea (tratado nessa contribuição como subgênero de Blabia) foi exclusivamente a presença de setas nos élitros de Blabia (Malthonea) e ausência de setas elitrais em Parablabia. Foi verificada a presença de setas muito curtas nos élitros das duas espécies incluídas em Parablabia e não foi possível constatar outros caracteres para distinguir os gêneros, o que determina sua sinonímia.

\section{Malthonea guttata (Kirsch, 1889) comb.n.}

Ptericoptus guttatus Kirsch, 1889: 40, est. 4, fig. 75.

Parablabia guttata; Breuning, 1959: 87; Monné, 1994: 66 (cat.).

O padrão do colorido elitral constituído por numerosas manchas castanhas salpicadas em fundo pálido é semelhante ao de Malthonea tigrinata Thomson e $M$. panthera Martins \& Galileo. M. guttata distingue-se de $M$. tigrinata: pubescência corporal amarelo-dourada sedosa; pronoto sem faixas longitudinais escuras, uniformemente pubescente; antenas, tíbias e tarsos vermelho-amarelados. Em M. tigrina$t a$ : pubescência corporal branco-acinzentada; pronoto com duas faixas paralelas de pubescência escura; antenas, tíbias e tarsos pretos. Além disso, $M$. guttata ocorre no noroeste da América do Sul e M. tigrinata na Floresta Atlântica meridional.

Malthonea guttata difere de $M$. panthera: pelo processo mesosternal sem tubérculo; pelo pronoto sem faixas longitudinais de pubescência escura; pelos espinhos laterais do protórax pouco projetados.

Material examinado. EQUADOR, Napo: Lago de Papallacta $(2 \mathrm{~km}$ NW de Papallacta, 3300m), 1 fêmea 11-X-1977, J. Rawlins, C. Young \& R. Davidson leg. (CMNH).

\section{Malthonea ruficornis Belon, 1903}

Malthonea ruficornis Belon, 1903: 61.

Parablabia ruficornis; Breuning, 1963: 514(cat.); Monné: 66(cat.)

Discussão. Pelo corpo uniformemente revestido de pubescência amarelodourada, sedosa e pelo processo mesosternal sem tubérculo, $M$. ruficornis assemelha-se à $M$. aurescens (Breuning) e M. mimula Martins \& Galileo. A distinção entre essas espécies encontra-se na chave a seguir.

Material examinado. BolíviA, La Paz: Sainani (Vale do Zongo, 2000m), macho 4-VIII-1993, A. Brescovit leg. (MZSP). 


\section{Malthonea cumbica sp.n.}

Fig. 4

Etimologia. Tupi Çumbica = roxo; alusivo ao colorido da face dorsal do corpo.

Macho. Tegumento corporal e dos apêndices preto. Dorso da cabeça e pronoto revestidos por pubescência azul com leve reflexo violáceo; élitros com pubescência violácea, brilhante. Fronte brilhante com alguns pontos pequenos, muito esparsos. Lobos oculares inferiores pouco mais longos do que as genas; lobos superiores com seis fileiras de omatídios, mais distantes do que o dobro da largura de um lobo. Antenas atingem o ápice elitral na extremidade do antenômero IX; flagelômeros basais com pêlos esparsos no lado interno. Pronoto com três gibosidades discretas: duas látero-anteriores e uma central ao nível do terço posterior. Disco pronotal com faixa estreita de pubescência branca; espinho lateral do protórax evidente com ápice voltado para cima. Ápice do escutelo recoberto por pubescência branca. Cada élitro com carena longitudinal paralela à sutura do terço basal à declividade apical; extremidades transversalmente truncadas com espículo externo. Processo mesosternal com tubérculo desenvolvido. Artículo I dos pro-e mesotarsos levemente intumescidos.

Dimensões. Comprimento total, 10,7; comprimento do protórax, 2,0; maior largura do protórax, 2,6; comprimento elitral, 7,8; largura umeral, 3,1.

Material-tipo. Holótipo macho. Venezuela, Merida: La Mucuy (2500m), 5-VI-1981, Bordón leg. (FAUV).

Discussão. Malthonea cumbica distingue-se prontamente de todas as espécies do gênero pelo colorido azul-violáceo da face dorsal do corpo e pelas extremidades elitrais transversalmente truncadas com espículo no lado externo.

\section{Chave para as espécies de Malthonea (modificada de MARTINS\& GALILEO 1995c)}

1. Processo mesosternal sem tubérculo . . . . . . . . . . . . . . . . . . . 2

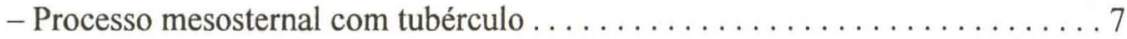

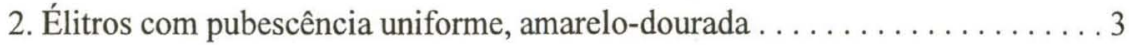

-Élitros com manchas de pubescência escura ou áreas glabras intercaladas . . . . 5

3. Lobos oculares inferiores mais longos que as genas; face ventral do corpo com tegumento avermelhado. Equador ........... aurescens (Breuning, 1966)

- Lobos oculares inferiores mais curtos que as genas; face ventral do corpo com

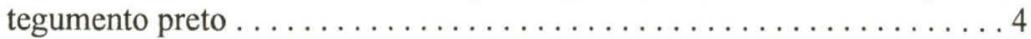

4. Espinhos laterais do protórax desenvolvidos, situados ao nível do terço posterior; comprimento total $10,0 \mathrm{~mm}$. Colômbia (Santander) .

- Espinhos laterais do protórax diminutos, situados ao nível do meio; comprimento total 5,6mm. Bolívia (Cochabamba) ........... ruficornis Belon, 1903 
5. Pronoto com pubescência acinzentada e duas faixas longitudinais escuras. Brasil

(Rio de Janeiro a Rio Grande do Sul), Argentina (Misiones) . . . . . . . . . triginata Thomson, 1864

- Pronoto com pubescência uniforme, sem faixas longitudinais escuras . . . . . 6

6. Antenas e pernas pretas; élitros com pubescência esbranquiçada marmorada por manchas castanhas; comprimento total 6,0-6,2mm. Peru (Huanuco, Cuzco) . . . . . . . . . . . . . . . . . . . minima Martins \&

- Antenas e pernas vermelho-amareladas; élitros com pubescência amarelo-dourada salpicados por manchas arredondadas de pubescência castanha; comprimento total 9,0-11,0mm. Colômbia. Equador. . guttata (Kirsch, 1889)

7. Cabeça, pronoto e élitros revestidos por pubescência azul-violácea; extremidades elitrais transversalmente truncadas com espículo no ângulo externo. Venezuela ............................. cumbica sp.n.

- Face dorsal do corpo sem pubescência azul-violácea; extremidades elitrais com espinho desenvolvido no lado externo .................. 8

8. Como no item 5 da chave em Martins \& Galileo (1995c).

\section{Cicuiara gen.n.}

Etimologia. Tupi cicuiára $=$ substituto, alusivo às mudanças nomenclaturais. Espécie-tipo. Exocentrus striatus Bates, 1866.

Corpo e apêndices desprovidos de setas longas. Fronte estreita. Lobos oculares inferiores muito desenvolvidos, quase ocupam todo lado da cabeça; lobos superiores separados por distância equivalente a pouco mais de uma fileira de omatídios (macho) ou por $c a$. três fileiras de omatídios (fềmea). Antenas com 11 artículos, atingem a ponta dos élitros na extermidade do antenômero VIII (macho) ou no ápice do IX (fêmea). Escapo cilíndrico, tão longo quanto o antenômero III que é tão longo quanto o IV. Antenômero V pouco mais curto que o IV; VI-XI gradualmente decrescentes em comprimento. Protórax mais largo do que longo com espinho nítido, curvo, ao nível do terço basal. Pronoto sem gibosidades. Élitros com pontuações (exceto região basal) organizadas em fileiras; extremidade arrendodada. Nos machos, processo prosternal e mesosternal muito estreitos, as procoxas quase contíguas e processo mesosternal sem tubérculo. Processos esternais nas fêmeas um pouco mais largos. Fêmures pedunculados e clavados. Mesotíbias com sulco no terço apical. Metatarsos apenas mais curtos que as metatíbias. Meso- e metatarsos com artículo I tão longo quanto o artículo V; artículo II com cerca de dois terços do comprimento do I.

Discussão. BATES (1866: 191) iniciou o estudo dos Desmiphorini do Vale do Amazonas com comentários sobre o gênero Exocentrus Mulsant, 1839, no qual descreveu duas espécies de Santarém, PA: E. striatus e E. nitidulus. Atualmente o gênero é composto por grande número de espécies não americanas (BREUNING 1963).

Melzer (1931: 73) ao estabelecer o gênero Cosmotomidus para Pogonocherus setosus A.-Serville, 1835, fez comentários sobre as espécies de Exocentrus 
descritas por Bates, já que no catálogo de GEMMINGer \& HAROLD (1873) P. setosus foi inserida em Exocentrus. MELzER (1931) não colocou no gênero Cosmotomidius nenhuma das duas espécies de Bates.

GiLmOUR (1965) ao tratar Acanthocinini no "Catalogue des Lamiaires du Monde" incluiu E. striatus e E. nitidulus em Cosmotomidus separados da espécietipo (C. setosus) por um ponto de interrogação, isto é, duvidou que as espécies pertencessem ao gênero. Esse mesmo tipo de citação foi feita por MONNÉ (1995).

Em resumo, as espécies de Bates nunca mais foram tratadas após a descrição original e atualmente encontram-se com dúvida no gênero Cosmotomidus.

Anota-se ainda que BATES (1866) indicou claramente que as espécies incluídas em Exocentrus distinguiam-se de todos os gêneros de Acanthocinini pelas cavidades coxais anteriores angulosas lateralmente. Acredita-se ter identificado corretamente a espécie que corresponde a Exocentrus striatus, que se redescreve abaixo e que se indica para espécie-tipo de Cuiciara gen.n.. Mantem-se, a exemplo de Bates, Cicuiara em Desmiphorini, embora o escapo seja alongado e delgado (como em Acanthocinini) com base no aspecto das cavidades coxais anteriores.

\section{Cicuiara stritata (Bates, 1866) comb.n.}

\section{Fig. 5}

Exocentrus stritatus Bates, 1866: 191.

Comotomidius? striatus; Monné, 1955: 152 (cat.)

Tegumento vermelho-acastanhado; base dos fêmures e metatíbias avermelhados. Fronte sem pontos grandes com pubescência esparsa; sutura frontal profunda prolongada até os lobos oculares superiores onde termina em pequena área brilhante. Antenas com pubescência esbranquiçada esparsa. Pronoto fina e densamente pontuado com pubescência branca não muito densa. Pontos elitrais densos, não organizados em fileiras no quarto basal e na declividade lateral; ao nível do meio, com nove fileiras longitudinais de pontos, cujos intervalos são recobertos por pubescência branca. Face ventral sem pontos, microesculturada, com pubescência branca.

Dimensões, macho/fêmea. Comprimento total, 5,9/6,4-8,2; comprimento do protórax, 1,2/1,2-1,6; maior largura do protórax, 1,6/2,0-2,4; comprimento do élitro, 4,1/4,5-5,9; largura umeral, 1,9/2,3-3,0.

Material examinado. Venezuela, Aragua: El Limon (450 m), macho, 13-VI-1982, B. Bechiné leg. (FAUV). BrasiL, Mato Grosso do Sul: Corumbá (Serra do Urucum), macho XI-1960, K. Lenko leg. (MZSP); Porto Murtinho (Várzea Alegre), fêmea XI-1927, W. Melzer leg. (MZSP). Goiás: Vianópolis, macho XI-1931, R. Spitz leg. (MZSP). Minas Gerais: Santa Bárbara (Serra do Caraça), fềmea 1-XII-1972, Exp. Mus. Zool. leg. (MZSP).

\section{Cicuiara nitidula (Bates, 1866) comb.n.}

Exocentrus nitidulus Bates, 1866: 191.

Cosmotomidus? nitidulus; Monné, 1995: 152 (cat.).

Não examinada, procedente de Santarém, Pará, Brasil. Propõe-se a transfe- 
rência para Cicuiara porque BATES (1866) incluiu-a em Exocentrus junto com E. striatus. Segundo a descrição original: comprimento 4,2 a $5,7 \mathrm{~mm}$; tegumento castanho-ferrugíneo, revestido por pubescência acinzentada curta; espinho lateral do protórax reto; pontos elitrais do disco parcialmente em fileiras; élitros finamente cobertos por pubescência cinérea, curta e brilhante. O material-tipo foi coletado sobre ramos finos, secos.
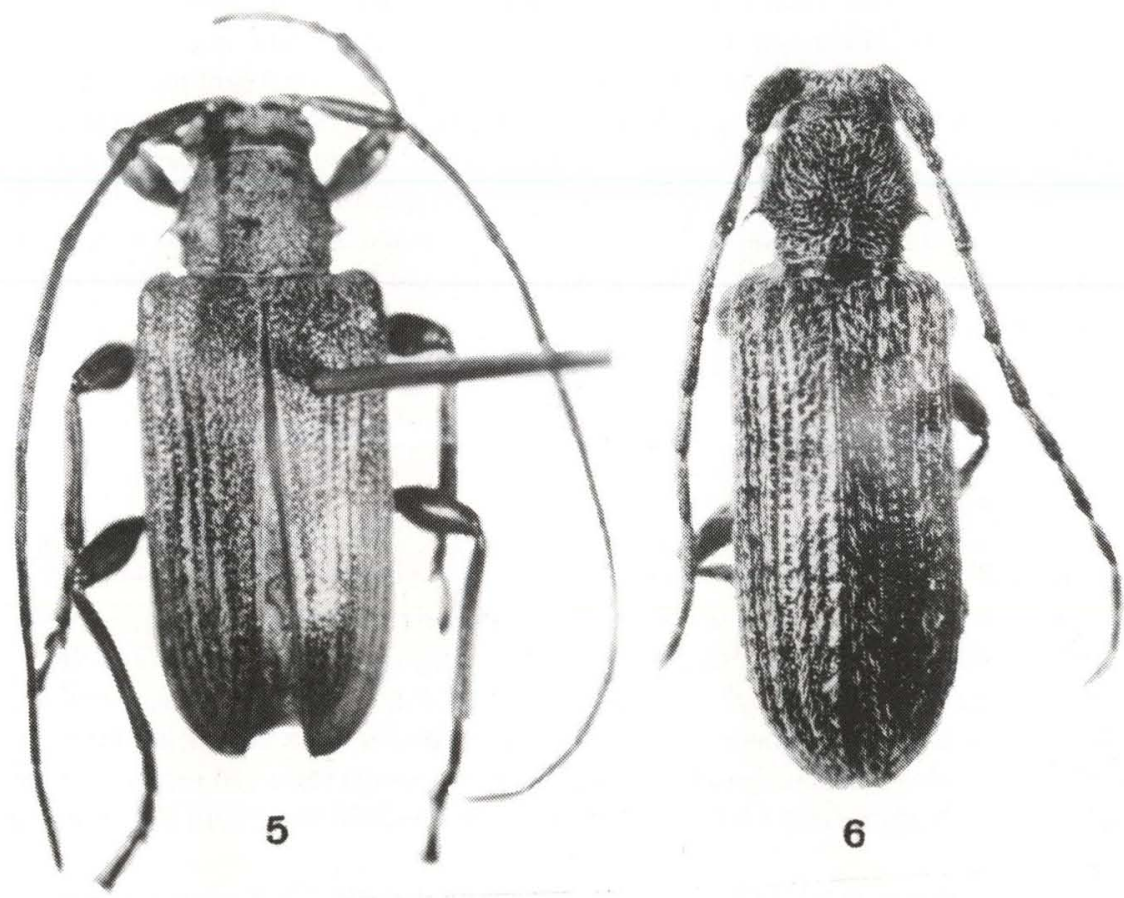

Figs 5-6. (5) Cuiciara striata (Bates, 1866), fêmea de Santa Bárbara (Serra do Caraça), comprimento, $7,2 \mathrm{~mm}$; (6) Mimasyngenes icuapara sp.n., holótipo fêmea, comprimento, $5,1 \mathrm{~mm}$.

\section{Mimasyngenes Breuning, 1950}

Mimasyngenes Breuning, 1950: 268; Monné, 1994: 62 (cat.).

Espécie-tipo, Mimasyngenes lineatipennis Breuning, 1950 (monotipia).

Caracteres adicionais à definição do gênero: lados da cabeça, abaixo dos lobos oculares nitidamente intumescidos. Distância entre os lobos oculares superiores variável; espinho lateral do protórax curto, cônico, situado ao nível do meio ou manifesto, algo recurvo para trás, situado ao nível do terço posterior; metafêmures dos machos nitidamente intumescidos; metatíbias (macho) engrossadas. 
Discussão. Na chave para gêneros de Desmiphorini (BREUNING 1974), Mimasyngenes situa-se entre Estolomimus Breuning, Euestola Breuning, Pseudestola Breuning, Neoestola Breuning e Dolichestola Breuning. Na realidade Mimasyngenes é muito diferente desse grupo de gêneros, cujas espécies apresentam setas muito curtas ou ausentes em todo corpo e pontuação elitral concentrada na base ou densa em toda a superfície. Em Mimasyngenes o corpo e os apêndices estão providos de setas muito longas e os élitros têm pontuação em geral fina e esparsa, o que permite separá-lo prontamente dos gêneros mencionados.

$\mathrm{O}$ aspecto geral e a fórmula antenal (antenômero III mais curto do que o IV) das espécies de Mimasyngenes assemelham-se aos Ceiupaba lineata que, contudo, apresenta protórax desarmado aos lados.

\section{Mimasyngenes lineatipennis Breuning, 1950}

Mimasyngenes lineatipennis Breuning, 1950: 269; Monné, 1994: 62 (cat.).

Lobos oculares superiores com cinco fileiras de omatídios, mais próximos entre si do que a largura de um lobo, mais desenvolvidos nos machos do que nas fêmeas. Espinho lateral do protórax cônico, perpendicular, não muito projetado. Pontuação pronotal fina, constituída por pontos alongados e transversais, alguns anastomosados. Élitros com faixas longitudinais de pubescência esbranquiçada pouco contrastantes mas perceptíveis. Metafêmures (macho) nitidamente engrossados na clava, com pubescência diferenciada (50x) numa área subcircular situada no lado dorsal da clava. Metatíbias nitidamente engrossadas.

Discussão. O holótipo foi fotografado por Moure no BMNH e é proveniente de Pernambuco, Brasil. Pode-se ler com clareza um rótulo com o nome de Gounelle. Os espinhos dos lados do protórax são discretamente mais projetados do que nos exemplares de Goiás que se atribui à espécie.

Moure fotografou ainda no NRMS um exemplar sob esta denominação, provavelmente de Chaco de Santiago, localidade mencionada por BREUNING (1974) para M. lineatipennis. Esse indivíduo obviamente pertence a espécie diferente, da qual não se dispõe de exemplares e o registro de M. lineatipennis para a Argentina deve ser eliminado.

Material examinado. BrasiL, Goiás: fêmea (MZSP, Gounelle det. como Exocentrus striatus); Jataí (Fazenda Aceiro), macho, fêmea, X-1962, Exp. Mus. Zool. leg. (MZSP).

\section{Mimasyngenes inlineatus Breuning, 1956}

Mimasyngenes inlineatus Breuning, 1956a: 357; Monné, 1994: 62 (cat.).

O material que agora se examina desta espécie, foi doado pelo CMNC e provém da Colômbia e da Venezuela. O macho apresenta metafêmures engrossados na clava com o mesmo tipo de área dorsal subcircular com pilosidade diferenciada, como em M. lineatipennis. Mimasyngenes inlineatus difere de M. lineatipennis, como já assinalara BREUNING (1974), pela ausência de faixas longitudinais de pubescência esbranquiçada nos élitros. 
Material examinado. ColôMBIA, Magdalena: Santa Marta (21 mi E), macho 18-V-1973, Campbell \& Howden leg. (MZSP). VENEZUELA, Tachira: Cordero (1200m), fêmea 22-V-1974, H. \& A. Howden leg. (MZSP).

\section{Mimasyngenes venezuelensis Breuning, 1956}

\section{Mimasyngenes venezuelensis Breuning, 1956b: 694; Monné, 1994: 62 (cat.)}

Não examinada, originalmente descrita de Caracas, Venezuela; o holótipo foi originalmente depositado na Coleção Lepesme, provavelmente incorporada ao MNHN. Segundo BREUNING (1974) é semelhante a M. lineatipennis por apresentar pubescência elitral esbranquiçada organizada em faixas longitudinais; difere: antenômero III apenas mais curto que o IV; pontuação do pronoto mais esparsa, os pontos não confluentes em pequenos sulcos transversais e base dos fêmures concolores, não avermelhadas.

\section{Mimasyngenes quiuira sp.n.}

Fig. 7

Etimologia. Tupi quiuira = irmão, alusivo à semelhança com M. lineatipennis.

Tegumento vermelho-acastanhado. Fronte microesculturada com alguns pontos maiores e pubescência branco-amarelada. Região lateral, abaixo e atrás dos olhos, acentuadamente intumescida. Lobos oculares superiores com 5 fileiras de omatídios, mais distantes entre si do que a largura de um lobo. Antenômero III um terço mais curto do que o IV. Espinho lateral do protórax evidente, acuminado, voltado para trás e situado ao nível do terço posterior. Pontos pronotais finos, transversais, constituindo fina rugosidade; pubescência fina, esparsa. Élitros esparsa e finamente pontuados; cada um com 4 fileiras longitudinais de fina pubescência branca, mais evidentes ao nível do meio. Metafêmures (macho) engrossados nos dois terços apicais; no lado externo do terço apical com área elíptica, glabra, que circunda pubescência branca e densa. Metatíbias (macho) intumescidas.

Dimensões. Comprimento total, 4,4-5,5; comprimento do protórax, 0,9-1,1; maior largura do protórax, 1,4-1,6; comprimento elitral, 3,1-4,0; largura umeral, $1,5-1,7$.

Material-tipo. Holótipo macho. BRASIL, São Paulo: Itapira, 3-XI-1962, E. Dente leg. (MZSP). Parátipos: 2 machos, 6 fêmeas, mesmos dados do holótipo, todos no MZSP, exceto: 1 fêmea (MCNZ); 1 fềmea (MNRJ).

Discussão. A pontuação do pronoto e o padrão de pubescência dos élitros é semelhante ao de $M$. lineatipennis. Difere pelos lobos oculares superiores mais distantes entre si do que a largura de um lobo e pelo espinho lateral do protórax acuminado com ápice voltado para trás e situado ao nível do terço basal. 

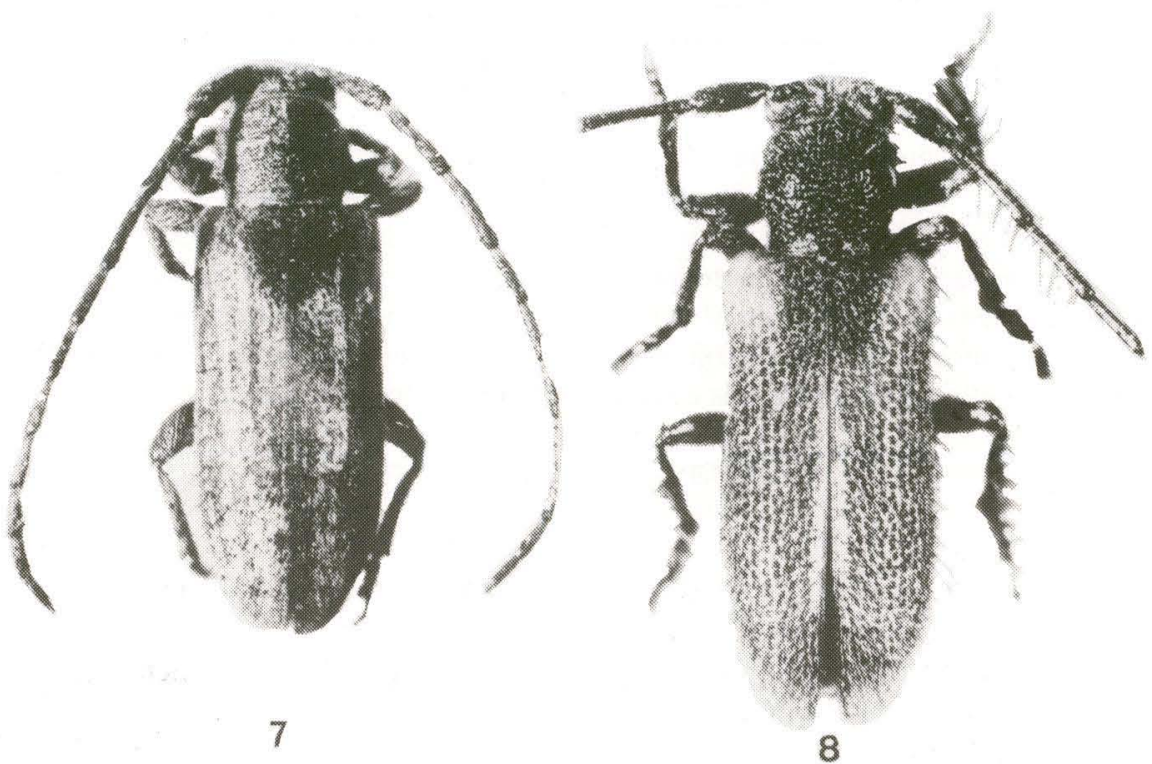

Figs 7-8. (7) Mimasyngenes quiuira sp.n., parátipo fêmea, comprimento, 4,5mm; (8) $M$. ytu sp.n., holótipo fêmea, comprimento, $4,4 \mathrm{~mm}$.

\section{Mimasyngenes icuapara sp.n.}

Fig. 6

Etimologia. Tupi içu= espinho; apára = torto; alusivo ao espinho nos lados do protórax.

Tegumento vermelho-acastanhado, mais escuro nas antenas e mais avermelhado nas bases dos profêmures. Pubescência corporal constituída por pêlos brancos, relativamente longos, grossos e não muito densos. Fronte fina e densamente pontuada. Região posterior aos lobos oculares inferiores intumescida. Lobos oculares superiores com 5 fileiras de omatídios, mais distantes entre si do que a largura de um lobo. Dorso da cabeça revestido por pubescência como a da fronte. Escapo e bases dos flagelômeros com o mesmo tipo de pubescência branca. Antenômero III apenas mais curto do que o IV. Espinho lateral do protórax fino, bem desenvolvido com ápice acuminado, voltado para trás e situado ao nível do terço posterior. Pronoto com pontos grossos e próximos. Pontuação elitral grossa e profunda; dorso da região central dos élitros com pontos organizados em fileiras longitudinais; entre as fileiras de pontos, situam-se faixas de pubescência branca e grosseira.

Dimensões. Comprimento total, 5,0-5,1; comprimento do protórax, 1,0; maior largura do protórax, 1,4-1,5; comprimento do élitro, 3,7; largura umeral, $1,5-1,6$. 
Material-tipo. Holótipo fêmea. Brasil, São Paulo: Itu (Fazenda Pau d'Alho), X. 1965, U. Martins leg. (MZSP). Parátipo: ArgentinA, Misiones, fêmea 20-I-1910, C. Bruch leg., ex-coleção Melzer (identificado por Bruch como Exocentrus sp.) (MZSP).

Discussão. Embora apresente faixas longitudinais de pubescência branca nos élitros, $M$. icuapara não pode ser confundida com $M$. lineatipennis ou com $M$. iquiuira. Em M. icuapara a pubescência é muito mais grosseira e longa, o pronoto e os élitros são densamente pontuados, estes com pontos do dorso organizados em fileiras. Além disso, difere de $M$. lineatipennis pelos lobos oculares superiores mais distantes entre si do que a largura de um lobo e pelo espinho do protórax bem desenvolvido, voltado para trás e situado ao nível do terço posterior.

\section{Mimasyngenes ytu sp.n.}

Fig. 8

Etimologia. Tupi $y t u$ = cachoeira; topônimo do estado de São Paulo; alusivo à localidade de coleta do parátipo.

Cabeça, antenas, protórax e face ventral do corpo com tegumento preto, brilhante, com leve reflexo azulado. Élitros castanho-avermelhados com leve reflexo azul-violáceo; região umeral largamente amarelada. Pernas com tegumento mais avermelhado. Fronte com pubescência branca algo grosseira e pouco densa. Região lateral da cabeça intumescida. Antenômero III apenas mais curto do que o IV. Espinho lateral do protórax desenvolvido, esbelto, acuminado com ápice voltado para trás e situado ao nível do meio. Pronoto densa e pronfudamente pontuado; pubescência muito fina e muito esparsa. Região umeral amarelada impontuada e glabra; restante da superfície elitral densamente pontuada; pontos da região centrodorsal organizados em fileiras longitudinais; pubescência elitral esbranquiçada, fina e uniformemente distribuída.

Dimensões. Comprimento total, 4,4; comprimento do protórax, 0,9; maior largura do protórax, 1,2; comprimento do élitro, 3,2; largura umeral, 1,4.

Material-tipo. Holótipo fêmea. Brasil, Minas Gerais: Belo Horizonte, O. Monte leg. (MZSP). São Paulo: Itu (Fazenda Pau d'Alho), parátipo (macho?, em mau estado de conservação), 28-29-X-1965, Martins \& Biasi leg. (MZSP).

Discussão. Mimasyngenes ytu caracteriza-se pelo padrão de colorido dos élitros com tegumento bicolor; em todas as demais espécies o tegumento elitral é unicolor.

\section{Chave para identificação das espécies de Mimasyngenes}

1. Espinho lateral do protórax cônico, curto, situado ao nível do meio; lobos oculares superiores mais próximos entre si do que a largura de um lobo ........ 2

- Espinho lateral do protórax fino, mais longo que o pedicelo com ápice voltado para trás; lobos oculares superiores mais distantes entre si do que a largura

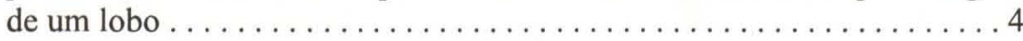

2. Pubescência esbranquiçada dos élitros fina e uniformente distribuída em toda a 
superfície. Colômbia, Venezuela . . . . . . . . inlineatus Breuning, 1956 - Pubescência esbranquiçada dos élitros ao nível do meio do dorso organizada em

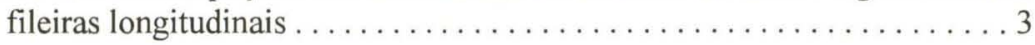

3. Pronoto com pontos finos, próximos, transversais e anastomosados que constituem aspecto de finas rugas transversais; base dos fêmures avermelhada. Brasil (Pernambuco, Goiás) ... . lineatipennis Breuning, 1950

- Pronoto com pontuação menos densa, os pontos não confluentes em sulcos transversais; base dos fêmures concolores. Venezuela . . . . . . . . . . . . venezuelensis Breuning, 1956

4. Élitros castanho-avermelhados com leve reflexo violáceo, a região umeral largamente amarelada e lisa; espinho lateral do protórax situado ao nível do meio. Brasil (Minas Gerais, São Paulo) . . . . . . . . . . . . ytu sp.n.

- Tegumento elitral uniformemente castanho-avermelhado; espinho lateral do

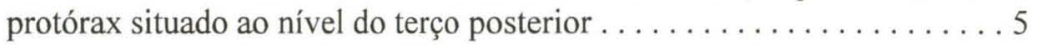

5. Pubescência esbranquiçada muito fina na cabeça, no pronoto e nos élitros; pronoto com pontuação finíssima; pontuação elitral esparsa (distância entre pontos do meio do dorso maior que o triplo do diâmetro dos pontos). Brasil (São Paulo), Argentina (Misiones) . .................. quiuira sp.n.

- Pubescência branca, grossa e longa na cabeça, no pronoto e nos élitros; pronoto densa e grosseiramente pontuado; pontuação elitral densa e profunda, nas fileiras do meio do dorso os pontos são subcontíguos. Brasil (São Paulo) . . icuapara sp.n.

\section{REFERÊNCIAS BIBLIOGRÁFICAS}

BATES, H.W. 1866. Contributions to an insect fauna of the Amazon Valley. Coleoptera: Longicornes. Subtribe Desmiphoritae Ann. Mag. nat. Hist., Londres, (3) 17: 191-202.

BELON, P.M. 1903. Matériaux pour l'étude des longicornes de Bolivie. Revue Ent., Caen, 22: 47-76.

BREUNING, S. 1940. Novae species Cerambycidarum. VIII. Folia zool. hydrobiol., Riga, 10: 115-214.

1950. Quelques nouveaux Lamiaires (Coleoptera, Cerambycidae) du Riksmuseum. Ark Zool., Uppsala, (2) 1: 265-274.

1956a. Noveaux Lamiaires du Riksmuseum (Col., Cerambycidae). Ark.

Zool. (n.s.), Uppsala, 9: 355-361.

1956b. Lamiaires nouveaux de la collection Lepesme (2e. note). Longicornia, Paris, 3: 665-702.

1959. Noveaux genres de Lamiinae (Coleoptera, Cerambycidae). Bull. Annls Soc. ent. Belgique, Bruxelles, 95: 70-88.

1963. Catalogue des Lamiaires du Monde. Parte 7. Tutzing bei München, Mus. G. Frey, p.463-555.

1974. Révision des Rhodopinini américains. Stud. ent., Petrópolis, 17: 
$1-210$.

GAliLEO, M.H.M. \& U.R. MARTINS. 1993a. Revisão do gênero Ischnolea Thomson, 1860 (Coleoptera, Cerambycidae, Lamiinae, Desmiphorini). Iheringia. Sér. Zool., Porto Alegre, (75): 63-79.

1993b. Revisão do gênero Panegyrtes Thomson, 1868 (Coleoptera, Cerambycidae, Lamiinae, Desmiphorini). Iheringia Sér. Zool., Porto Alegre (75): 89-96.

- no prelo. Gênero Panegyrtes Thomson, 1868 (Coleoptera, Cerambycidae, Lamiinae, Desmiphorini): novas espécies e chave para identificação. Revta bras. Ent., São Paulo.

Gemminger, M. \& E. von HAROLD. 1873. Catalogue Coleopterorum hucusque descriptorum synonymicus et systematicus. Monachii, 10: 2989-3232.

Gilmour, E.F. 1965. Catalogue des Lamiaires du Monde. Parte 8. Tutzing bei München, Mus. G. Frey, p. 559-653.

KIRSCH, T.F. 1889. Coleopteren gesammelt in den Jahren 1868-1877 auf einen

Reise durch Sud Amerika von Alphons Stübel. Abh. Ber. zool. Mus. Dresden, Dresden, 4: 1 - 58.

MARTINS, U.R. \& M.H.M. GALILEO. 1994. Revisão do gênero Stereomerus Melzer, 1934 (Coleoptera, Cerambycidae, Lamiinae, Desmiphorini). Papéis Avulsos Zool., São Paulo, 39 (1): 1-11.

—. 1995a. Os gêneros Coeloprocta Aurivillius, 1926; Anisopeplus Melzer, 1934 e Acaya gen.n. (Coleoptera, Cerambycidae, Lamiinae, Desmiphorini). Revta bras. Zool., Curitiba, 12 (1): 25-29. 1995b. Notas e descrições em Desmiphorini (Coleoptera, Cerambycidae). Iheringia, Sér. Zool., Porto Alegre, 78: 161-170.

. 1995c. Revisão do gênero Malthonea Thomson, 1864 (Coleoptera, Cerambycidae, Lamiinae, Desminhorini). Revta bras. Ent., São Paulo, 39 (3): 611-621.

1995d. Revisão do gênero Blabia Thomson, 1864 (Coleoptera, Cerambycidae, Lamiinae, Desmiphorini). Revta bras. Ent., São Paulo, 39 (3): 567-590.

Melzer, J. 1931. Longicorneos americanos, principalmente do Brasil, novos ou pouco conhecidos. Arch. Inst. Biol., São Paulo, 4: 51-82.

MONNÉ, M.A. Catalogue of the Cerambycidae (Coleoptera) of the Western Hemisphere. Part XVI. São Paulo, Sociedade Brasileira de Entomologia, 98p. . 1995. Catalogue of the Cerambycidae (Coleoptera) of the Western Hemisphere. Part XVIII. São Paulo, Sociedade Brasileira de Entomologia, 196p.

THOMSON, J. 1864. Systema cerambycidarum ou exposé de tous les genres compris dans da famille des cerambycides et families limitrophes. Mém. Soc. r. Sci. Liège 19: 1-540.

Recebido em 08.V.1996; aceito em 02.XII.1996. 